\title{
PENERAPAN CUSTOMER RELATIONSHIP MANAGEMENT (CRM) TERHADAP LOYALITAS PELANGGAN (studi kasus bank BNI cabang palopo)
}

\author{
Anne Attas', M. Risal ${ }^{2}$, Muhammad Yusuf Qamaruddin ${ }^{3}$, Rahmad Solling Hamid \\ Email : ${ }^{1)}$ anneattas1995@gmail.com, ${ }^{2)}$ mrisal@stiem.ac.id, ${ }^{3)}$ yusufq@ $@$ stiem.ac.id, \\ ${ }^{4)}$ rahmadhamid@stiem.ac.id \\ ${ }^{1,2,4)}$ Prodi Manajemen, Sekolah Tinggi Ilmu Ekonomi Muhammadiyah Palopo \\ ${ }^{3)}$ Prodi Ilmu Ekonomi Pembangunan, Sekolah Tinggi Ilmu Ekonomi Muhammadiyah \\ Palopo
}

\begin{abstract}
Abstrak
Tujuan penelitian adalah untuk menguji apakah ada pengaruh Customer Relationship Management (CRM) terhadap Loyalitas Pelanggan dan untuk menguji seberapa besar pengaruh Customer Relationship Management (CRM) terhadap Loyalitas Pelanggan. Penelitian ini dilakukan dengan menyebarkan kuesioner kepada masyarakat di kota Palopo, yang pernah melakukan transaksi perbankan di PT Bank BNI Tbk Cabang Palopo. Pengujian dan pengolahan data menggunakan perangkat lunak SPSS dengan bantuan regresi dan metode korelasi sederhana. Hasil penelitian menunjukkan bahwa Customer Relationship Management (CRM) mempengaruhi Loyalitas Pelanggan.
\end{abstract}

Kata Kunci: Customer Relationship Management, Loyalitas Pelanggan.

\section{PENDAHULUAN}

Perusahaan di Indonesia dari tahun ke tahun berkembang dengan pesat. Pesatnya peningkatan perusahaan tersebut menimbulkan tingginya tingkat persaingan sehingga mengakibatkan setiap manajemen harus dapat mengelola perusahaannya secara maksimal dan profesional, agar memiliki kualitas yang baik dalam menghadapi daya saing yang tinggi. (Pradhana, 2011).

Daya saing yang tinggi merupakan indikator kinerja perusahaan yang baik. Untuk itu setiap perusahaan harus meningkatkan mutu pelayanan terhadap pelanggannya. Kualitas layanan merupakan aspek penting dalam menjaga loyalitas pelanggan. Perusahaan yang gagal memberikan kepuasan bagi pelanggannya akan menghadapi masalah yang lebih kompleks dikarenakan munculnya dampak bad word of mouth (seperti: protes, complaint, atau pun kritikan) dari pelanggan.

Persaingan dalam dunia bisnis mendorong setiap perusahaan untuk dapat menciptakan inovasi-inovasi terbaru mengenai cara mempertahankan dan mendapatkan customer atau pelanggan. Bahkan cara mempertahankan dan menjalin hubungan dengan pelanggan juga berlaku di berbagai perspektif, termasuk pandangan dalam perspektif Islam. Dalam Islam seorang penjual dianjurkan menjalin hubungan baiknya dengan pembeli, untuk memperlakukannya dengan baik supaya terjalin ikatan yang saling menguntungkan bagi kedua belah pihak. Hubungan baik yang terjalin diharapkan ada kecocokan dan kesinambungan sebagai ikatan bisnis yang dibentuk karena suka sama suka, saling memberikan manfaat, saling percaya antara penjual dan pembeli, tidak hanya untuk mencari keuntungan semata, namun ada nilai kebersamaan untuk saling menjaga hubungan kerjasama yang telah dibangun dalam ikatan persaudaraan.

Bank merupakan perusahaan yang selalu ingin memberikan kualitas pelayanan yang maksimal bagi nasabahnya. Bank adalah lembaga keuangan yang tugasnya memberikan jasa keuangan melalui penitipan uang (simpanan), peminjaman uang (kredit), serta jasa-jasa keuangan lainnya. Untuk itu, Bank harus dapat menjaga kepercayaan yang diberikan oleh nasabah. Kepercayaan yang telah diberikan oleh nasabah harus selalu dijaga dan ditingkatkan dengan cara bahwa bank perlu membangun suatu citra positif di mata masyarakat. Citra positif tersebut dapat 
dibentuk melalui kualitas produk, kualitas pelayanan dan kualitas keamanan. Tanpa citra positif di mata masyarakat, maka kepercayaan yang sedang dan akan dibangun akan sia-sia (Kasmir, 2011).

Selain menjaga citra yang positif dari nasabah, Bank juga mempunyai tujuan utama dari strategi pemasarannya yaitu untuk meningkatkan jumlah nasabahnya, baik secara kuantitas maupun kualitas. Untuk mencapai tujuan tersebut maka memberikan kepuasan nasabah merupakan salah satu tindakan yang harus dilakukan oleh perusahaan. Sehingga muncul slogan bahwa pelanggan itu penting dan mereka adalah raja, yang harus dilayani dengan sebaik-baiknya.

Dalam dunia perbankan, melayani, menjaga atau pun menjalin hubungan dengan nasabah sangatlah penting. Sehingga dibentuk divisi/bidang public relations di perusahaan mereka untuk memperoleh citra positif dari publik. Public relations merupakan fungsi manajemen yang mengevaluasi perilaku publik, mengidentifikasi kebijaksanaan dan prosedur organisasi dengan interes publik dan melaksanakan program tindakan (komunikasi) untuk mendapatkan pemahaman dan pengertian publik. (Alo Liliweri, 2011). Perkembangan teknologi informasi yang semakin merambah berbagai aplikasi bisnis, menjadikan CRM sebagai salah satu proses ataupun strategi bisnis yang menarik untuk diperbincangkan. Kegiatan marketing mengelola seluruh aspek dari daur hidup pelanggan. CRM merupakan strategi komprehensif dari perusahaan agar setiap proses dari daur ulang hidup pelanggan itu dapat dimanfaatkan dengan optimal. CRM merujuk pada software system yang membantu perusahaan memperoleh dan menyimpan data pelanggannya serta melakukan hubungan dua arah, guna memperoleh kepuasan pelanggannya.

Berdasarkan latar belakang masalah tersebut, maka rumusan masalah dari penelitian ini yaitu

: Apakah terdapat tingkat Customer Relationship Management (CRM) terhadap Loyalitas Pelanggan PT Bank BNI Cabang Palopo?"

\section{METODE PENELITIAN}

Lokasi penelitian ini bertempat pada PT. Bank BNI Cabang Palopo penelitian ini di laksanakan setelah seminar proposal, penelitian dilaksanakan yaitu antara bulan mei sampai juni kurang lebih 2 bulan setelah seminar proposal. Dalam penelitian ini jenis data yang digunakan adalah data kuantitatif. Adapun sumber data yang digunakan adalah data primer. Data Primer adalah data yang diperoleh secara langsung dari hasil pengamatan pada objek penelitian yaitu pada nasabah Bank BNI Cabang Palopo.

Populasi dalam penlitian ini adalah nasabah pada PT. Bank BNI Cabang Palopo, sedangkan dalam penentuan jumlah sampel, responden menggunakan rumus slovin sehingga diperoleh jumlah sampel sebanyak 100 orang.

Untuk menghitung dan menganalisis Analisis data dalam penelitian dilakukan dengan menggunakan bantuan program SPSS. Adapun persamaan dari regresi sederhana adalah sebagai berikut Sugiyono dan Wibowo (2002:35):

Keterangan :

$$
\mathbf{Y}=\mathbf{a}+\mathbf{b X}+\mathbf{e}
$$

$\mathrm{X}=\mathrm{CRM}$

$\mathrm{Y}=$ Loyalitas Pelanggan

$\mathrm{a}=$ Konstanta (nilai $\mathrm{Y}^{\mathrm{ee}}$ apabila,....Xn $=0$ )

$\mathrm{b}=$ Koefisien regresi (nilai peningkatan

ataupun penurunan)

$\mathrm{e}=$ Eror

\section{HASIL DAN PEMBAHASAN}

\section{Uji Parsial (Uji T)}

Uji $\mathrm{t}$ dilakukan untuk mengetahui ada tidaknya pengaruh secara parsial variabel independen terhadap variabel dependen. Adapun tingkat signifikansi yang digunakan sebesar 0,05. Jika probabilitas $<0,05$ maka variabel independen secara parsial mempunyai pengaruh signifikan terhadap variabel dependen. 


\section{Hasil Uji t}

\begin{tabular}{|c|c|c|c|c|c|c|}
\hline \multirow{2}{*}{\multicolumn{2}{|c|}{ Model }} & \multicolumn{2}{|c|}{$\begin{array}{c}\text { Unstandardized } \\
\text { Coefficients }\end{array}$} & \multirow{2}{*}{\begin{tabular}{|c|}
$\begin{array}{c}\text { Standardized } \\
\text { Coefficients }\end{array}$ \\
Beta \\
\end{tabular}} & \multirow[t]{2}{*}{$\mathrm{t}$} & \multirow[t]{2}{*}{ Sig. } \\
\hline & & $\mathrm{B}$ & Std. Error & & & \\
\hline \multirow{2}{*}{1} & (Constant) & 13.704 & 1.328 & & 10.321 & .000 \\
\hline & CRM & .234 & .076 & .174 & 3.074 & .002 \\
\hline
\end{tabular}

a. Dependent Variable: Loyalitas Pelanggan

Sumber: Output SPSS 21.0, 2017

Penerapan dari Customer Relationship

Management (CRM) Terhadap Loyalitas Pelanggan Pada PT. Bank BNI Cabang Palopo dapat dilihat dari arah tanda dan tingkat signifikan (probabilitas). Variabel terhadap signifikan minat Loyalitas Pelanggan.

Nilai thitung pada variabel Customer Relationship Management (X) menunjukkan nilai t hitung sebesar 3.074 koefisien regresi sebesar 0.174 dan nilai probabilitas (sig) sebesar 0,002 yang tidak lebih besar dari 0,05 hal ini berarti bahwa $\mathrm{H}_{1}$ diterima dan $\mathrm{H}_{0}$ ditolak dengan kata lain Customer Relationship
Management (CRM) Berpengaruh Terhadap Loyalitas Pelanggan.

\section{KoefisienDeterminasi $\left(\mathbf{R}^{2}\right)$}

Dalam suatu penelitian mengenai hubungan antar variabel tidak bebas dan variabel bebas sering ingin diketahui beberapa kekuatan $\mathrm{X}$ secara bersama-sama menerangkan perubahan pada Y. koefisien korelasi berganda (R) dan koefisien determinasi $\left(\mathrm{R}^{2}\right)$ dapat dilihat pada hasil SPSS ver.21 dibawah ini

\section{Uji KoefisienDeterminasi $\left(\mathbf{R}^{2}\right)$}

\begin{tabular}{|l|r|r|r|r|}
\hline Model & \multicolumn{1}{|c|}{$\mathrm{R}$} & \multicolumn{1}{c|}{ R Square } & Adjusted R Square & Std. Error of the Estimate \\
\hline 1 & $.174^{\mathrm{a}}$ & .030 & .027 & 1.65735 \\
\hline
\end{tabular}

Sumber: Output SPSS 21.0, 2017

Dari tabel diatas terlihat tampilan output SPSS Model Summary bersama Adjusted $R$ quare adalah 0.027 atau 27\%. Hal ini menunjukkan bahwa variabel bebas (X) secara bersama-sama memberikan kontribusi terhadap variabel terikat (Y) sebesar $27 \%$, sedangkan sisanyan $73 \%$ dipengaruhi oleh variabel lain yang tidak dimasukkan dalam penelitian ini.

\section{PEMBAHASAN HASIL PENELITIAN}

Berdasarkan hasil linear sederhana diketahui tingkat signifikan untuk masing-masing variabel tersebut yaitu nilai $t_{\text {hitung }}$ pada variable CRM (X) menunjukkan nilai t hitung sebesar 3.074 koefisien regresi sebesar 0.174 dan nilai probabilitas (sig) sebesar 0,002 yang tidak lebih besar dari 0,05 hal ini berarti bahwa $\mathrm{H}_{1}$ diterima dan $\mathrm{H}_{0}$ ditolak dengan kata lain customer relationship management berpengaruh terhadap loyalitas pelanggan.

\section{SIMPULAN DAN SARAN}

Berdasarkan analisis yang telah dilakukan dapat ditarik kesimpulan bahwa Hasil penelitian menunjukkan diatas menunjukkan customer relationship management (CRM) berpengaruh segnifikan secara positif terhadap loyalitas pelanggan dan memiliki peluang besar dalam mengembangkan (CRM) pada Bank atau perusahaan-perusahaan lain. Hasil penelitian perhitungan uji $\mathrm{T}$ diatas yaitu nilai $t_{\text {hitung }}$ pada variable $C R M(\mathrm{X})$ menunjukkan nilai t hitung sebesar 3.074 koefisien regresi sebesar 0.174 dan nilai probabilitas (sig) sebesar 0,002 yang tidak lebih besar dari 0,05 hal ini berarti bahwa $\mathrm{H}_{1}$ diterima dan $\mathrm{H}_{0}$ ditolak dengan kata lain 


\section{customer relationship management}

berpengaruh terhadap loyalitas pelanggan.

Berdasarkan hasil dan kesimpulan yang didapatkan, maka beberapa saran yang dapat diajukan yaitu Bagi PerusahaanDalam mengembangkan produk dan jasa yang ditawarkan, perusahaan harus mempertimbangkan kebutuhan nasabah yang selalu berubah. Keunggulan yang telah diraih saat ini tetap perlu dikembangkan dan terus disempurnakan untuk setiap produk atau jasa perusahaan dengan menambahkan berbagai fitur layanan baru untuk meningkatkan kenyamanan pelanggan dalam menggunakan layanan transaksi perbankan pada PT. Bank BNI Cabang Palopo.

\section{DAFTAR PUSTAKA}

Kasmir. 2011. Manajemen Perbankan, Ed Revisi. Jakarta: Rajawali Pers.

Liliweri, A. 2010. Komunikasi serba ada serba makna. Jakarta: Kencana.

Sugiyono \& Wibowo, E. 2003. Statistik untuk penelitian. Bandung: Alfabeta.

Pradhana, O. D. 2011. Analisa dan Desain dengan Metode CRM (Customer Relationship Management) pada Pengelolaan Data Dream Paradise Bali Tour \& Travel. Skripsi "pdf”,(Surabaya: UPN "Veteran" Jawa Timur, 2011) hal, 1 . 